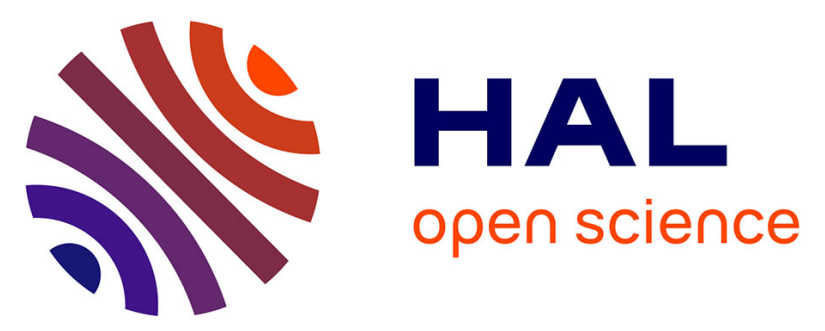

\title{
Investigating Light-Driven Hole Injection and Hydrogen Evolution Catalysis at Dye-Sensitized NiO Photocathodes: A Combined Experimental-Theoretical Study
}

Julien Massin, Maximilian Bräutigam, Sebastian Bold, Maria Wächtler, Michèle Pavone, Ana B. Muñoz-García, Benjamin Dietzek, Vincent Artero, Murielle Chavarot-Kerlidou

\section{- To cite this version:}

Julien Massin, Maximilian Bräutigam, Sebastian Bold, Maria Wächtler, Michèle Pavone, et al.. Investigating Light-Driven Hole Injection and Hydrogen Evolution Catalysis at Dye-Sensitized NiO Photocathodes: A Combined Experimental-Theoretical Study. Journal of Physical Chemistry C, 2019, 123 (28), pp.17176-17184. 10.1021/acs.jpcc.9b04715 . hal-02266505

\section{HAL Id: hal-02266505 \\ https://hal.science/hal-02266505}

Submitted on 18 Oct 2021

HAL is a multi-disciplinary open access archive for the deposit and dissemination of scientific research documents, whether they are published or not. The documents may come from teaching and research institutions in France or abroad, or from public or private research centers.
L'archive ouverte pluridisciplinaire HAL, est destinée au dépôt et à la diffusion de documents scientifiques de niveau recherche, publiés ou non, émanant des établissements d'enseignement et de recherche français ou étrangers, des laboratoires publics ou privés. 


\section{Investigating Light-Driven Hole Injection and Hydrogen Evolution Catalysis at Dye-Sensitized NiO Photocathodes: a combined experimental-}

\section{theoretical study}

Julien Massin, ${ }^{a}$ Maximilian Bräutigam, ${ }^{b, c}$ Sebastian Bold, ${ }^{a, b, c}$ Maria Wächtler, ${ }^{b, c}$ Michele

Pavone, ${ }^{e}$ Ana B. Muñoz-Garcia, ${ }^{d *}$ Benjamin Dietzek, ${ }^{b, c, f *}$, Vincent Artero ${ }^{a}$ and Murielle Chavarot-Kerlidou ${ }^{a *}$

a - Laboratoire de Chimie et Biologie des Métaux, Université Grenoble Alpes, CNRS, CEA, 17 rue des Martyrs, 38000 Grenoble, France.

b - Institute of Physical Chemistry and Abbe Center of Photonics, Friedrich Schiller University Jena, Helmholtzweg 4, 07743 Jena, Germany.

c - Department Functional Interfaces, Leibniz Institute of Photonic Technology Jena (IPHT), Albert-Einstein-Straße 9, 07745 Jena, Germany.

d - Department of Physics "Ettore Pancini”, University of Naples Federico II, Complesso Universitario Monte Sant'Angelo Via Cintia, 80126 Naples, Italy.

e - Department of Chemical Sciences, University of Naples Federico II, Complesso Universitario Monte Sant'Angelo Via Cintia, 80126 Naples, Italy. f - Center for Energy and Environmental Chemistry, Friedrich Schiller University Jena, Philosophenweg 8, 07743 Jena, Germany.

\footnotetext{
Abstract

Dye-sensitized photo-electrochemical cells (DS-PECs) form an emerging technology for the large-scale storage of solar energy in the form of (solar) fuels because of the low cost and ease to process of their constitutive photoelectrode materials. Such hybrid photoelectrodes are based on molecular dyes grafted onto transparent semiconducting metal oxides and also contain catalytic
} 
centers. The optimization of the performances of such hybrid photoelectrodes requires a detailed understanding of the light-driven electron transfer processes occurring first at the interface between the semi-conducting material and the dye and then between the dye and the catalytic center. Here we address the first of these issues and use quantum chemistry to determine the structural and electronic features of the interfaces between a push-pull dye and the p-NiO (100) surface. We show that these calculations are in good agreement with transient absorption spectroscopic measurements on a prototypical dye-sensitized photocathode system able to evolve hydrogen in the presence of a cobaloxime catalyst in solution.

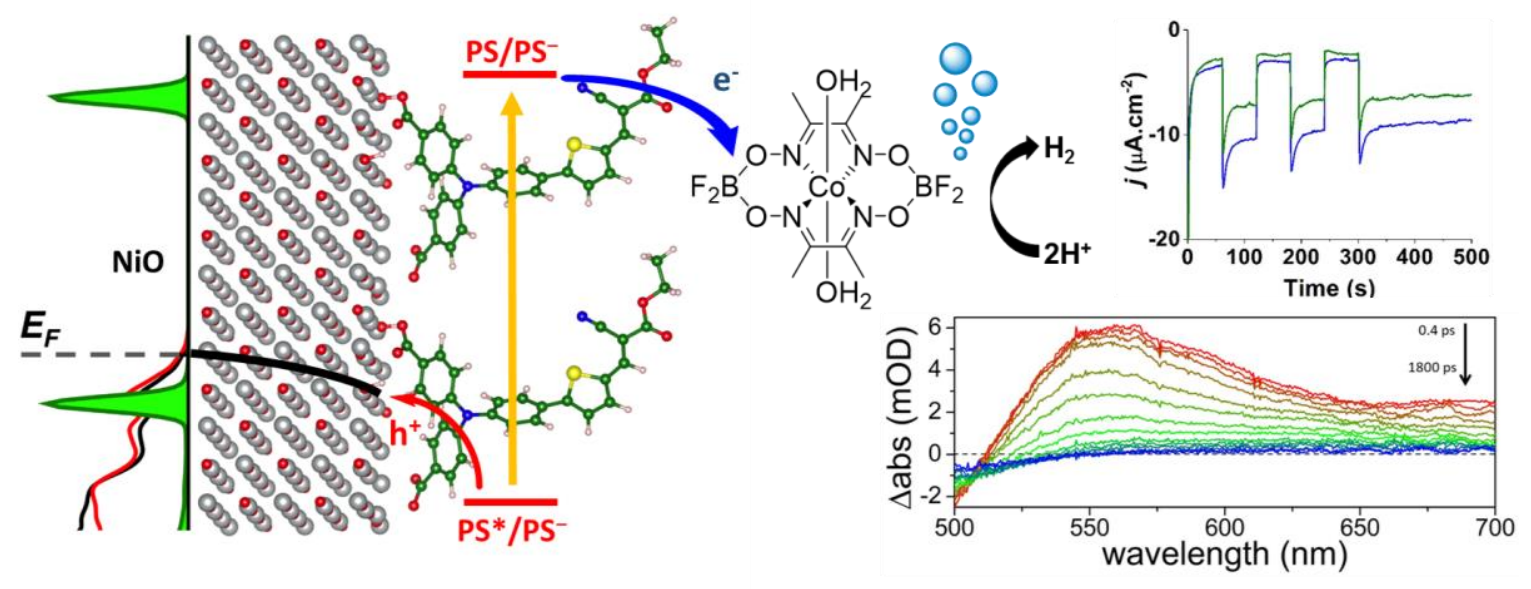

Keywords: Solar fuels, dye-sensitized photoelectrodes, DSPEC, NiO, push-pull dye, cobaloxime, transient absorption measurements.

\section{Introduction}

The production of fuels through light-driven processes is a promising solution for the durable storage of solar energy. ${ }^{1-2}$ Among other technologies, photoelectrochemical cells (PECs) couple the harvesting of light with fuel-forming catalysis in a single device. ${ }^{3}$ Dye-sensitized PECs (DSPECs) form a particular class of such devices based on the grafting of active photocatalytic components at the surface of transparent conductive electrode substrates, extending the tandem dye-sensitized solar cells (DSSCs) technology. ${ }^{4-6}$ Significant achievements in this direction have been reported recently regarding the preparation of molecular-based photocathodes active for $\mathrm{H}_{2}$ production or $\mathrm{CO}_{2}$ reduction, including their implementation in operating DS-PECs. ${ }^{7-11}$ Almost all of them rely on nickel oxide $(\mathrm{NiO})$, which is a low-cost and easy-to-process $p$-type 
semiconductor, suitable for hole injection from an excited molecular photosensitizer to its valence band. ${ }^{11-28}$ Various nanostructured $\mathrm{NiO}$ film preparation methods have been reported over the years ${ }^{29}$ and recently evaluated with respect to their performance as photocathodes in a comprehensive benchmarking study. ${ }^{30}$

Irrespective of the molecular design of the photocathode, i.e. the specific nature/structure of dyes and catalysts that are employed and how they are assembled (catalyst dissolved in solution $v s$. co-grafting of dye and catalyst onto $\mathrm{NiO} v s$. covalent dye-catalyst assembly), two key kinetic processes for the photoelectrocatalytic activity can be identified: i) light-driven charge separation and hole injection into $\mathrm{NiO}$ and ii) generation of a long-lived charge-separated intermediate to cope with the low timescale of catalysis compared to the light-driven processes. ${ }^{31}$ In order to meet these key requirements, organic push-pull dyes have advanced into versatile sensitizer systems, ${ }^{4,32}$ even though the injection kinetics observed for $\mathrm{Ru}(\mathrm{II})$-bipyridyl-derived complexes have also been discussed in the context of intramolecular push-pull properties. ${ }^{33-35}$ Generally, such chromophores are designed to have their HOMO localized near the NiO surface and the LUMO distant to it. Thus, their excited states are ideally suited to promote electron injection from occupied $\mathrm{NiO}$ levels, more specifically $\mathrm{Ni} d$ and $\mathrm{O}_{\mathrm{NiO}} p$ states, into the HOMO of the electronically excited photosensitizer. Coumarin C343-sensitized $\mathrm{NiO}$ films were among the first studied systems for elucidating electron transfer dynamics by ultrafast spectroscopic techniques, ${ }^{36-38}$ including light-driven electron transfer to a co-grafted $\mathrm{H}_{2}$-evolving catalyst. ${ }^{18,}{ }^{39-}$ ${ }^{41}$ This motivated two of us to investigate the structure, energetics and electronic properties of the $\mathrm{NiO}(100) / \mathrm{C} 343$ interface by an original ab initio study which highlighted how the local molecular structure at the interface can affect relevant parameters for performance, such as the dye binding strength or the dye-electrode hole injection driving force. ${ }^{42}$

We now extend this study to $\mathrm{NiO}$ electrodes functionalized by a push-pull organic dye. Grafted onto $\mathrm{NiO}$, the $\mathbf{T} 1$ dye containing a triarylamine electron-donor part and an ethyl cyanoacetate electron-acceptor part separated by a thiophene unit (Fig. 1) was proven efficient to generate photocurrents in the presence of irreversible electron acceptors in aqueous electrolytes. ${ }^{43}$ To characterize the initial light-driven processes occurring at $\mathrm{NiO}$ electrodes sensitized with $\mathbf{T 1}$, we use the ab initio approach to get insights into the thermodynamics of the hole injection process, we characterize this process kinetically using ultrafast transient absorption spectroscopy and 
finally demonstrate that light-driven charge separation at this dye-sensitized $\mathrm{NiO}$ electrode can be coupled to $\mathrm{H}_{2}$ evolution catalysis under fully aqueous conditions.

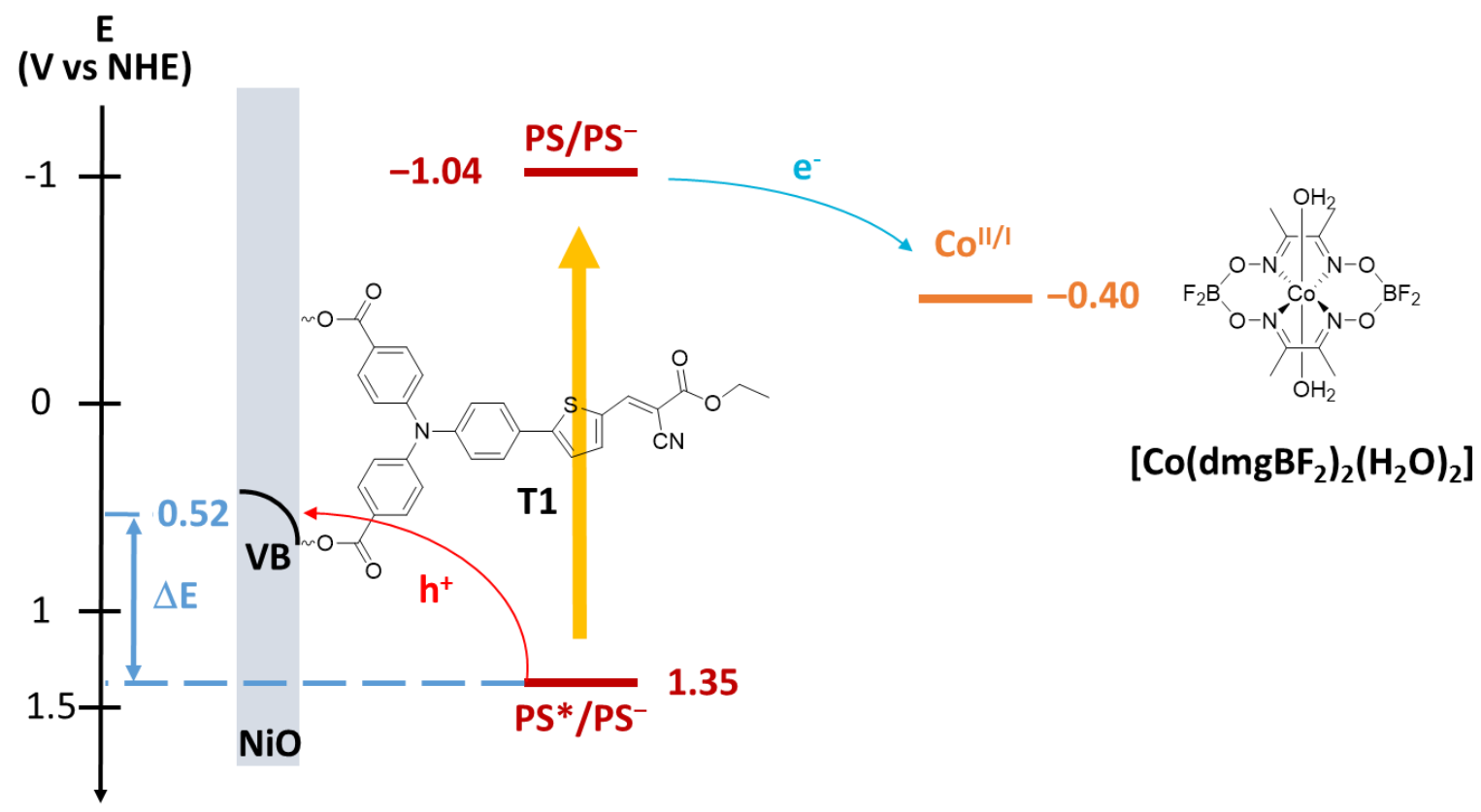

Figure 1. Energy level diagram at $\mathrm{pH} 4.5$ of a p-type $\mathrm{NiO}$ photocathode sensitized with $\mathbf{T 1}$, together with the chemical structure and $\mathrm{Co}^{\mathrm{II}} / \mathrm{Co}^{\mathrm{I}}$ redox potential (vs. NHE) of the $\mathrm{H}_{2}$-evolving cobaloxime catalyst $\left.\left[\mathrm{Co}\left(\mathrm{dmgBF}_{2}\right)_{2}\left(\mathrm{H}_{2} \mathrm{O}\right)\right]_{2}\right]$. The $\mathrm{NiO}$ valence band edge potential at this $\mathrm{pH}$ value was estimated from the $0.37 \mathrm{~V}$ vs. NHE value determined at $\mathrm{pH} 7 .^{44}$

\section{Results and discussion}

\section{DFT Calculations}

HOMO and LUMO densities of the isolated T1 dye (Fig. S1) are typical for a push-pull dye, with a significant part of the HOMO and LUMO density localized on the anchoring and acceptor group, respectively. Since $\mathbf{T} 1$ features two carboxylic acid anchoring groups, we have considered two different binding geometries corresponding to one and two carboxylate groups attached to a $\mathrm{NiO}$ (100) surface, which we call mono-branch $(\mathbf{M})$ and bi-branch (B) throughout the text (Fig. 2). In both cases, we have considered the bidentate anchoring mode for the carboxylate groups, which exhibits $\sim 0.12 \mathrm{eV}$ more negative binding energies than the monodentate one. ${ }^{42}$ 

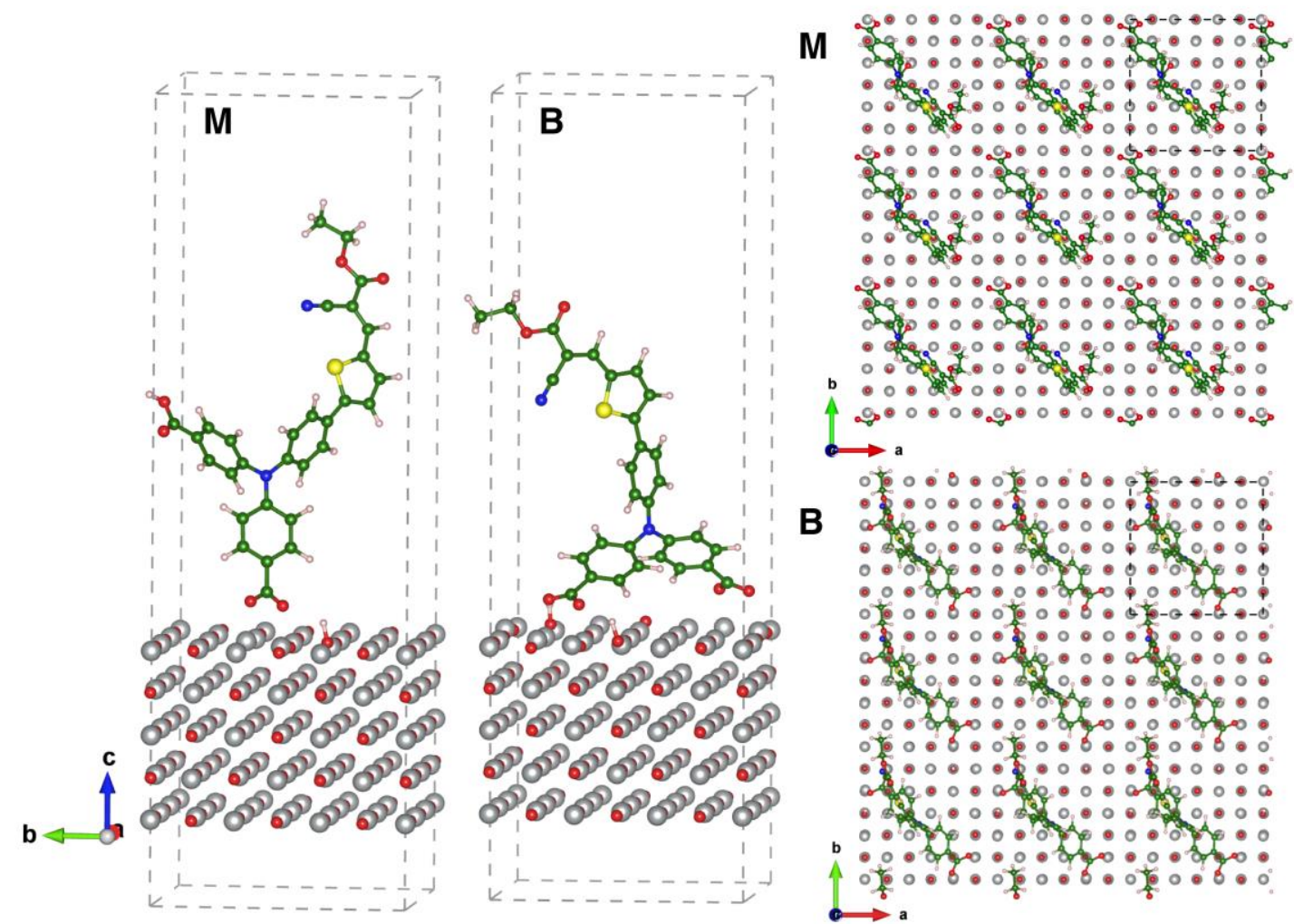

Figure 2. Left: Lateral views of the optimized structures of $\mathbf{T} 1$ dye upon adsorption on NiO (100) surface in the mono-branch $(\mathbf{M})$ and bi-branch $(\mathbf{B})$ adsorption modes. The limits of the unit cell used are shown in dashed grey. Right: Top view of $3 \times 3$ unit cells of $\mathbf{M}$ and $\mathbf{B}$ systems. Color legend: Ni (silver), O (red), C (green), N (blue), S (yellow), H (light pink).

For both the $\mathbf{M}$ and $\mathbf{B}$ configurations we found energy minima, as confirmed by harmonic molecular frequencies calculations. Of course, other local minima can be found because of the dye's flexible tail, but an extensive sampling of the dye conformational space is beyond the scope of this work, which is focused on the T1-NiO interface rather than on the dye molecular dynamics. Moreover, we checked the effects of dispersion on the dye binding energy by including the D3 correction scheme by Grimme, ${ }^{45}$ but we find no qualitative differences with pristine DFT-PBE $+\mathrm{U}$, the $\mathbf{B}$ case always slightly favored over the $\mathbf{M}$ geometry with and without the inclusion of dispersion forces. On these structural minima, we have evaluated the thermodynamic driving force for hole injection ( $\Delta E$ in Fig. 1) from the corresponding atomprojected density of states (PDOS) of $\mathbf{M}$ and $\mathbf{B}$ systems (Fig. 3). Resulting values for $\Delta E$ are collected in Table 1. In all three environments considered (vacuum, acetonitrile and water), hybridized $\mathrm{Ni} d$ - and $\mathrm{O} p$-states cross the Fermi level and are above the dye HOMO energies, 
resulting in a favorable $\Delta E$ for hole injection. Still, we find that the solvent strongly affects the relative position of the $\mathrm{NiO}_{\mathrm{vB}}-\mathbf{T 1}_{\text {номо }}$ peaks, bringing a very weak driving force for hole injection in vacuum $(0.05 \mathrm{eV})$ to a very convenient driving force of $0.26 \mathrm{eV}<\Delta E<0.35 \mathrm{eV}$ in acetonitrile and water. This effect is related to the solvent offsetting the interfacial electrostatic dipole generated by the surface $\mathrm{OH}$ groups upon bidentate binding of the carboxylate groups. While qualitatively similar, $\mathbf{M}$ systems present $\sim 0.1 \mathrm{eV}$ of extra driving force with respect to $\mathbf{B}$ ones in both acetonitrile and water.
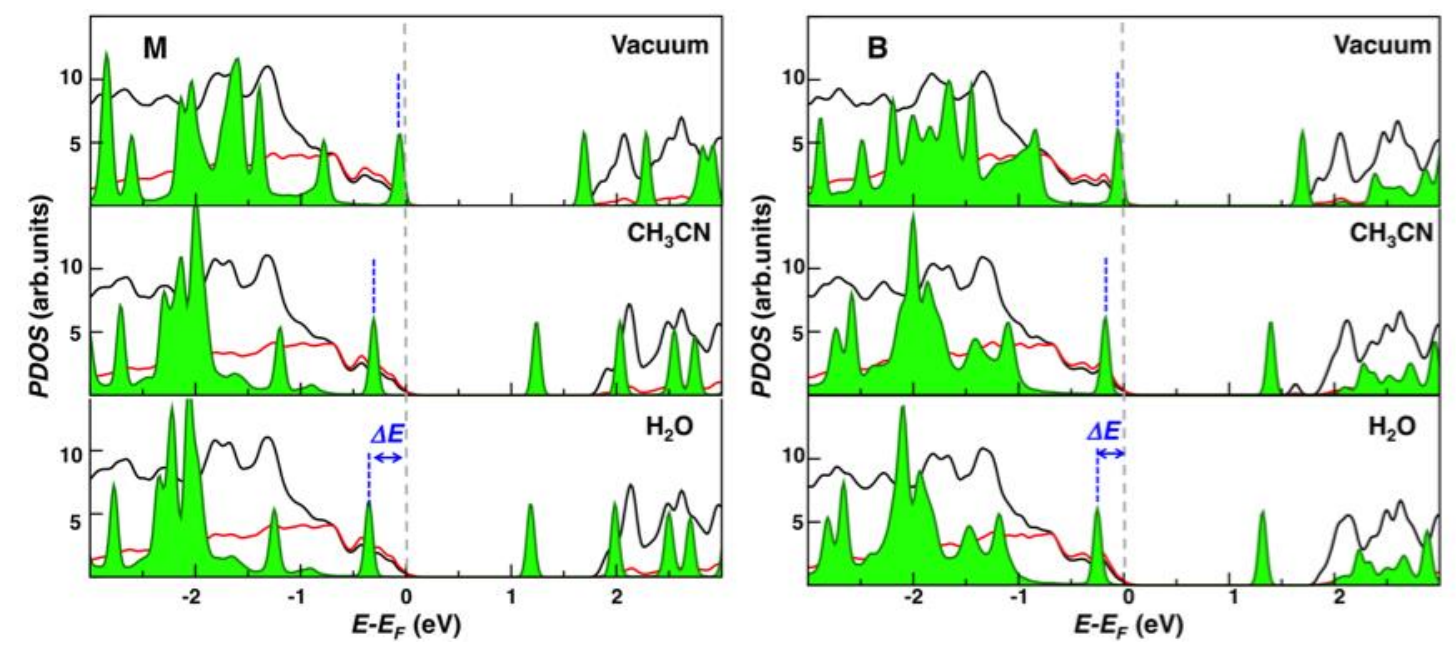

Figure 3. Projected density of states (PDOS) at the DFT-PBE+U level of theory for Ni $d$ states (black line), $\mathrm{O}_{\mathrm{NiO}} p$ states (red line) and $\mathbf{T} 1$ dye (green line) in the $\mathbf{M}$ and $\mathbf{B}$ adsorption mode calculated in vacuum (top panels), acetonitrile (central panels) and water (bottom panels). The Fermi energy $\left(E_{F}\right)$ is set to zero. Corresponding $\Delta E$ values are reported in Table 1.

Table 1. Calculated driving force for hole injection $(\Delta E)$, calculated as the energy difference between the highest occupied PDOS peak of the dye and the Fermi level (p-NiO VB edge, the highest energy occupied state in the VB).

\begin{tabular}{|c|c|c|}
\hline $\boldsymbol{\Delta} \boldsymbol{E}(\mathbf{e V})=\boldsymbol{E}_{\mathrm{F}}-\boldsymbol{E}_{\text {Hомо }}$ & $\mathbf{M}$ & $\mathrm{B}$ \\
\hline $\mathbf{V a c u u m}$ & -0.05 & -0.05 \\
\hline $\mathbf{C H}_{3} \mathbf{C N}$ & -0.30 & -0.18 \\
\hline $\mathbf{H}_{2} \mathbf{O}$ & -0.35 & -0.26 \\
\hline
\end{tabular}

Besides presenting a good thermodynamic driving force for hole injection, the recombination of the excited electron of the dye with the holes at the semiconductor valence band should be minimized in efficient p-DSSCs. We have evaluated this effect by obtaining the band- 
decomposed charge densities of $\mathbf{M}$ and $\mathbf{B}$ systems for the lowest-energy unoccupied band as an approximation of the LUMO of the dye when attached to NiO. These charge densities provide qualitative insights into where the electron will reside after photo-excitation of the dye. As shown by Fig. 4, in both M and B cases, the pseudo-LUMO densities are localized on the T1 dye electron-acceptor group, as the LUMO of the isolated dye (Fig. S1). On the contrary, for the nonpush-pull benchmark C343 dye (Fig. 4, right) the pseudo-LUMO density is not only localized on the dye, but involves a significant amount of unoccupied states from the electrode surface slab. From electron transfer theory applied to p-DSSCs, ${ }^{46}$ the probability of charge recombination is inversely proportional to the distance between the dye photo-excited electron and the hole at the electrode surface. While for the $\mathrm{C} 343-\mathrm{NiO}$ system this distance is practically zero, the $\mathrm{T} 1$ pseudo-LUMO density stays well localized on the electron-acceptor group and at a reasonable distance from the $\mathrm{NiO}$ surface $(>10 \AA)$. So, it is expected that recombination processes are minimized for $\mathbf{T} 1$ adsorbed on $\mathrm{NiO}$.
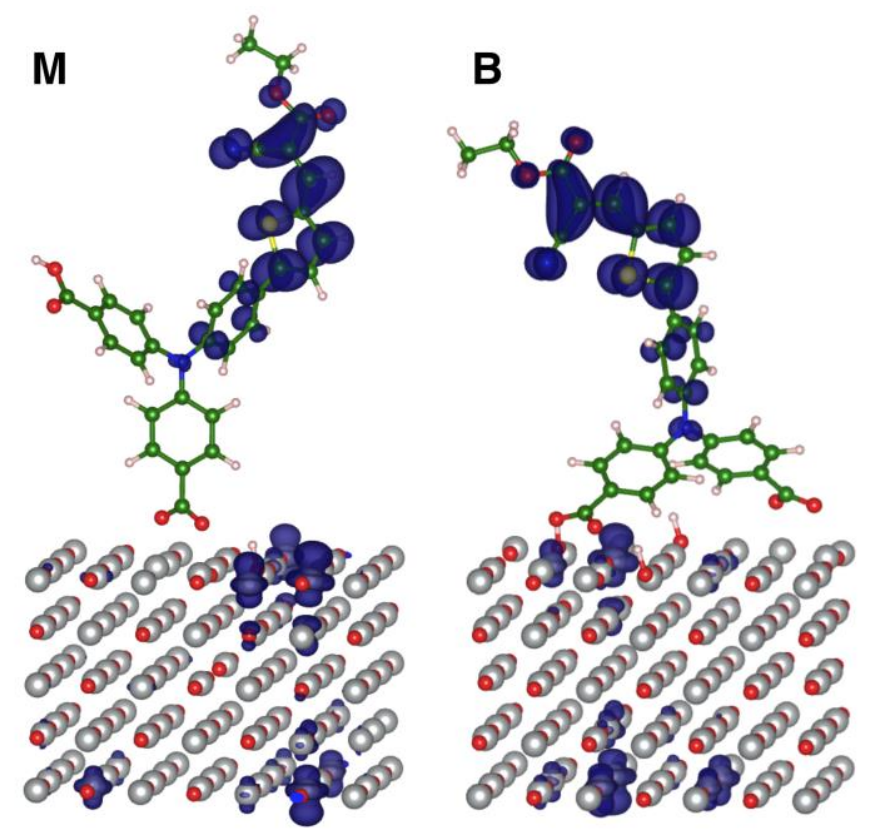

C343

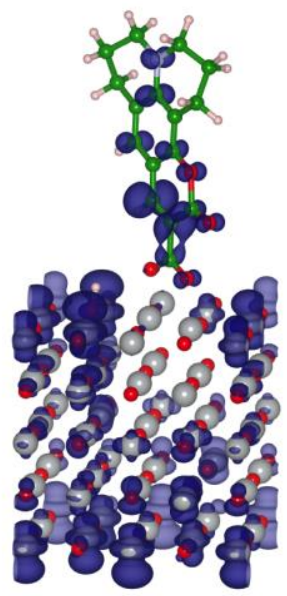

Figure 4. Isosurfaces of band-decomposed charge density of the lowest unoccupied bands of adsorbed $\mathbf{T 1}$ in both $\mathbf{M}$ (left) and $\mathbf{B}$ (middle) adsorption modes on $\mathrm{NiO}$ (100) in comparison with that of coumarine $\mathrm{C} 343$ dye (right) computed at the same level of theory $\left(\mathrm{PBE}+\mathrm{U}, \mathrm{H}_{2} \mathrm{O}\right.$ - implicit solvent). Isosurface value: $0.001 e^{-}$bohr $^{-3}$. 
We must note that these results can only provide qualitative insights. On one hand, the quite large size of the system, including the $\mathbf{T 1}$ dye, the NiO slab and the implicit solvent, prevents an ab initio characterization beyond state-of-the-art DFT-PBE+U (as for example GW approaches): we must note, for example, that for a correct description of the $\mathrm{NiO}$ conduction band an hybrid HF-DFT approach with $\sim 35 \%$ of exact exchange would be better suited than DFT-PBE+U [ref]. On the other hand, the $\mathrm{p}-\mathrm{NiO} / \mathrm{T1} /$ solvent interface is still a very simplified model of a much more complex real electrode, where several other species are involved in a complex surface equilibrium. Still, our computational results highlight the different contributions of the adsorption mode (M vs $\mathbf{B}$ ) and of the solvent polarity on (i) the hole injection driving force and (ii) the probability of charge recombination, setting the conceptual framework for the analysis of the spectrocopic and the electrochemical results (see below).

\section{Transient absorption spectroscopy}

Time-resolved transient absorption measurements were performed for $\mathbf{T} 1$ dissolved in acetonitrile and grafted onto mesoporous $\mathrm{NiO}$ films, both in the presence and in the absence of chenodeoxycholic acid (CDCA). CDCA is a well-established co-adsorbent in dye-sensitized solar cells to avoid aggregation of sensitizer on the surface of $\mathrm{TiO}_{2}$ and hence to reduce dye-dye interactions, which are prone to quench excited states and hence diminish the efficiency of the solar cells. $^{47-48}$

In solution, the transient spectra immediately after excitation are dominated by positive excited state absorption (ESA) for wavelengths shorter than $600 \mathrm{~nm}$ and longer than $650 \mathrm{~nm}$ (Fig. 5A). The negative feature between 600 and $650 \mathrm{~nm}$ results from dominating contributions from stimulated emission (SE), which is supported by comparison with the absorption and emission spectrum of the dye in solution. Contributions originating from ground state bleach (GSB) can be ruled out because the ground state is not absorbing in this spectral region. Within the first 4 ps the negative SE feature between 600 and $650 \mathrm{~nm}$ disappears while in parallel negative signal is formed for wavelengths longer than $650 \mathrm{~nm}$. These changes probably result from a change in the ESA band superimposed on the SE contributions to the overall transient spectrum, but also an additional redshift of the SE signal on this time scale can contribute to the observed spectral 
changes. After $4 \mathrm{ps}$ an overall decay of the signal intensity without significant changes in the spectral shape is observed (Fig. 5B). These observations can be explained in line with the established model for the relaxation in the excited state manifold in structurally related push-pull systems upon intra-molecular charge-transfer $\left({ }^{1} \mathrm{ICT}\right)$ excitation. ${ }^{49-51}$ A relaxation cascade leads from the initially populated $\mathrm{ICT}_{\mathrm{FC}}$ state to a relaxed ${ }^{1} \mathrm{ICT}$ states. In $\mathbf{T 1}$ a relaxed emissive ICT' state is formed with a time constant of $\tau_{1}=0.9 \pm 0.1 \mathrm{ps}$ leading to the strong spectral changes observed in the transient spectra occurring up to 4 ps. This ICT' state is depopulated via emission and/or ISC. The decay of the overall signal can be fitted with two exponentials, $\tau_{2}=$ $118 \pm 10 \mathrm{ps}$ and $\tau_{3}=1.9 \pm 0.4 \mathrm{~ns}$. The value of $\tau_{3}=1.9 \mathrm{~ns}$ agrees with the lifetime of $1.7 \mathrm{~ns}$ determined by emission lifetime measurements (Fig. S5). The observed spectral signatures and photoinduced processes are not impacted by the presence of CDCA (Fig. S6). 

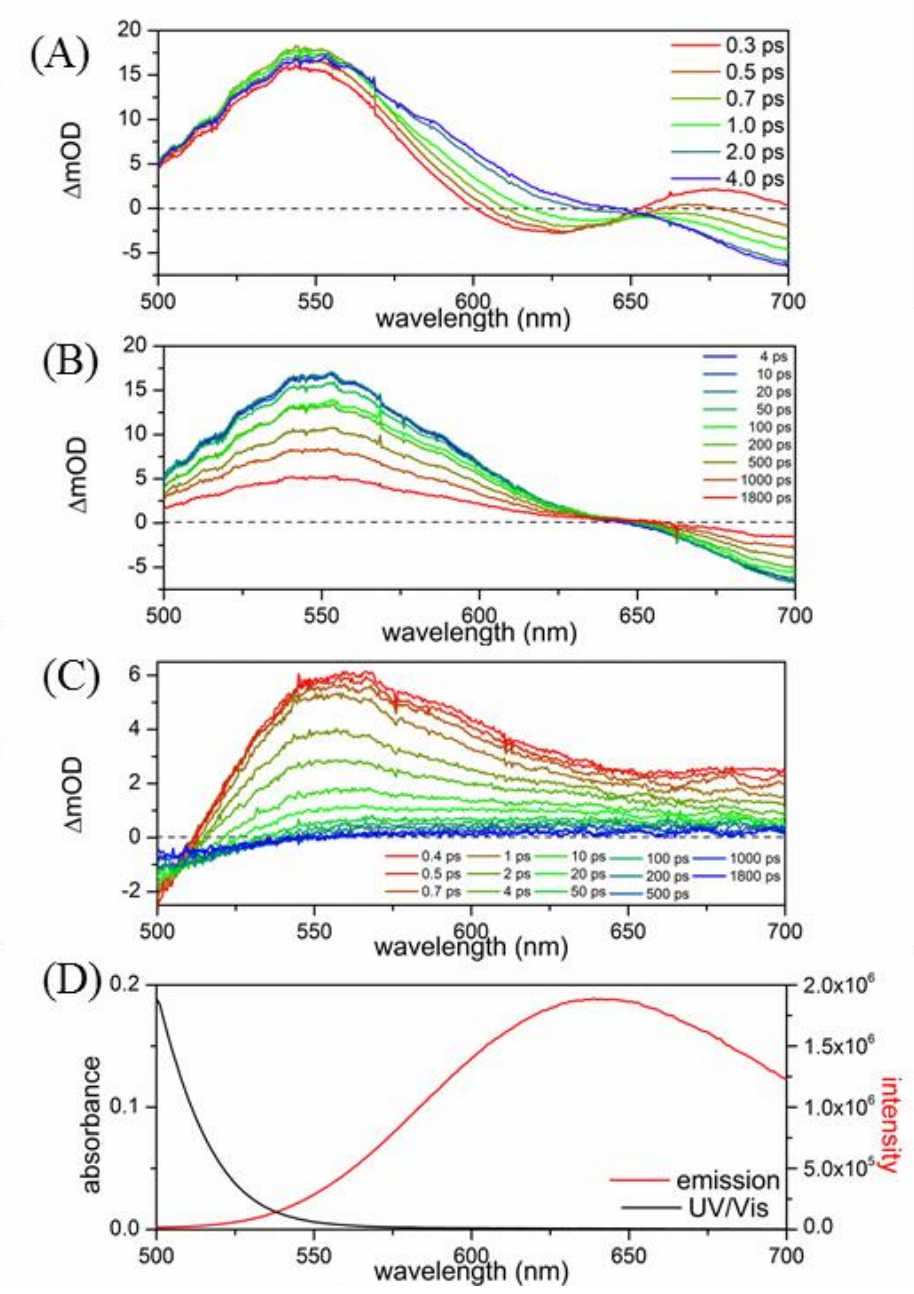

Figure 5. Transient absorption spectra of $\mathbf{T 1}$ in acetonitrile solution (A, B) and of a $\mathrm{NiO}$ film sensitized with T1 (C) at chosen delay times. The steady state absorption and emission $\left(\lambda_{\mathrm{ex}}=\right.$ $400 \mathrm{~nm}$ ) spectra of $\mathbf{T 1}$ are given for comparison in the relevant spectral range (D).

When grafted onto $\mathrm{NiO}$, the transient spectra show negative contributions below $530 \mathrm{~nm}$ which is assigned to GSB by comparison with the absorption spectrum of the dye (Fig. 5D). The spectral region above $530 \mathrm{~nm}$ is dominated by a broad absorption feature with a maximum at 550 $\mathrm{nm}$. The absence of any stimulated emission signal when attached to the NiO surface is an indication for a very fast and quantitative hole injection into the $\mathrm{NiO}$ after photoexcitation. The overall signal intensity decays over the entire range of delay times experimentally accessible. The maximum levels off during the decay and the remaining signal at the maximum delay investigated (1.8 ns) consists of negative contributions below $550 \mathrm{~nm}$ and a shallow positive feature above $550 \mathrm{~nm}$ with no distinct maximum. The photoinduced absorption signal for T1@NiO decays almost completely within 2 ns. The rates for hole injection and recombination 
were determined by a global fit of the data with a sum of multiexponential functions. The characteristic time-scales obtained from the global data analysis are $\tau_{1}=400 \mathrm{fs}, \tau_{2}=1.8 \mathrm{ps}, \tau_{3}=$ $16 \mathrm{ps}$ and $\tau_{4}=280 \mathrm{ps}$ and a low-amplitude long-lived signal remains visible in the data (Table 2 and Fig. S6). To experimentally address the question whether the packing of $\mathbf{T 1}$ on the $\mathrm{NiO}$ surface impacts the dynamics, T1 and CDCA were co-grafted onto the NiO electrodes. CDCA was indeed previously employed as anti-aggregation agent to improve the photovoltaic efficiency of DSSCs. ${ }^{47-48}$ As shown in the supporting information (Fig. S3, S4 and S6), the addition of CDCA does not impact the photoinduced processes, i.e. characteristic time-constants of $\tau_{1}=300 \mathrm{fs}, \tau_{2}=1.7 \mathrm{ps}, \tau_{3}=17 \mathrm{ps}$ and $\tau_{4}=266 \mathrm{ps}$ plus a long lived low amplitude component result from the fit (Table 2 and Fig. S6). Hence, interactions between individual T1 molecules can be excluded to account for the observed photoinduced dynamics in the T1-sensitized NiO electrodes.

Table 2. Time constants $\left(\tau_{\square}\right)$ derived from a global multiexponential fit, for amplitude spectra (decay associated spectra - DAS) see Fig. S6, and relative decay amplitude (A) for the bleach formed on $\mathrm{NiO}$ in the spectral range between $500 \mathrm{~nm}$ and $510 \mathrm{~nm}$ determined by integration of the signal in this range.

\begin{tabular}{|l|c|c|c|c|}
\hline & $\mathbf{T 1}\left(\mathrm{CH}_{3} \mathrm{CN}\right)$ & $\mathbf{T 1}+\mathrm{CDCA}\left(\mathrm{CH}_{3} \mathrm{CN}\right)$ & $\mathbf{T 1} @ \mathrm{NiO}$ & $\mathbf{T 1}+\mathrm{CDCA} @ \mathrm{NiO}$ \\
\hline$\tau_{1} / \mathbf{p s}\left(\mathbf{A}_{1}\right)$ & 0.9 (n.a.) & 0.8 (n.a.) & $0.4(0.17)$ & $0.3(0.21)$ \\
\hline$\tau_{2} / \mathbf{p s}\left(\mathbf{A}_{2}\right)$ & 118 (n.a.) & 70 (n.a.) & $1.8(0.13)$ & $1.7(0.34)$ \\
\hline$\tau_{3} / \mathbf{p s}\left(\mathbf{A}_{3}\right)$ & & & $16(\approx 0)$ & $17(\approx 0)$ \\
\hline$\tau_{4} / \mathbf{p s}(\mathbf{A 4})$ & & & $280(0.35)$ & $266(0.20)$ \\
\hline$\tau_{5} / \mathbf{n s}(\mathbf{A} 5)$ & $\sim 1.8$ (n.a.) & $\sim 1.8$ (n.a.) & $>1.8(0.35)$ & $>1.8(0.33)$ \\
\hline
\end{tabular}

The thermodynamic driving force calculated to $0.3 \mathrm{eV}$ (see above) is reflected in the rather rapid electron injection visible in the transient absorption data shown in Fig. 5C. From the data, a characteristic injection time of $\tau_{1}=0.3 \pm 0.1$ ps can be deduced. Probably even faster components contribute to the charge injection, which are hidden by the coherent artifact. ${ }^{52-53}$ This sub-ps timescale for hole injection is consistent with literature, e.g. a recent study by Hammarström and coworkers, who use a push-pull chromophore structurally related to P1, for covalent attachment of a Co-based molecular catalyst. ${ }^{21}$ However, these authors observed in addition a second 
injection time constant in the ps-range, which is absent in our experiments. Instead, on the ps to ns timescale we observe an overall decay of the transient absorption signal, which is characterized by ground-state bleach below roughly $525 \mathrm{~nm}$ and a rather broad photoinduced absorption band peaking at $555 \mathrm{~nm}$ and occurs multiexponentially. Such multiexponential decay, reflecting the (partial) charge recombination, is typical for dye-sensitized semiconductors and can be associated with (a) charge-recombination from holes of different natures, i.e. localized in the VB or trapped in surface and/or in intra-band states, ${ }^{54-57}$ (b) different molecular conformations of the reduced photosensitizer (c) different localizations of the radical anion. The latter is particularly apparent when using transition metal complexes as photosensitizers, in which the photoactive core consists of an asymmetrically coordinated redox active metal ion, e.g. $\mathrm{Ru}(\mathrm{II}) .{ }^{34}$ Associated with the overall decay of the photoinduced absorption signal of T1@NiO is a shift of the zero-crossing of the $\Delta \mathrm{OD}$-signal from $515 \mathrm{~nm}$ (at early delay times) to $530 \mathrm{~nm}$ (at long delay times). This indicates that recombination of holes in the $\mathrm{NiO}$ with the reduced photosensitizer occurs fast - as typically observed for NiO photocathodes. ${ }^{58}$ The sub-ns timescale of charge recombination, processes associated with the characteristic time constant $\tau_{2}=280 \mathrm{ps}$, is kinetically very much like the data reported by Hammarström et al., who reported charge recombination times of $335 \mathrm{ps}$ in a structurally very related system. ${ }^{21}$ Interestingly, charge recombination for $\mathbf{T} 1 @ \mathrm{NiO}$ is one order of magnitude slower than the one previously reported for coumarin $\mathrm{C} 343 @ \mathrm{NiO}$ (characteristic time constant of $23 \mathrm{ps}$ ), ${ }^{36}$ as predicted by our DFT calculations (see above).

Nonetheless, the decay of the photoinduced signal is not complete within the experimentally accessible delay times of $1.8 \mathrm{~ns} .{ }^{21}$ We cannot quantify the actual timescale for the slow charge recombination, which is outside the range of experimentally accessible delay times. Meyer and coworkers resorting to a cathode architecture, in which the photosensitizer and the $\mathrm{NiO}$ are separated by an extended supramolecular spacer, reported charge separation lifetimes extending $\mu$ s to ms. ${ }^{55}$ To estimate the yield of this long-lived species, we compared the amplitudes of the ground-state bleach signal measured at the very blue edge of the experimentally accessible spectral window (to avoid contributions from the overlaying broad and red-shifted photoinduced absorption band). At a delay time of 400 fs the ground-state bleach has an amplitude of about 2.5 $\mathrm{mOD}$, which decays to $1 \mathrm{mOD}$ at $1.8 \mathrm{~ns}$ delay time. From the relative amplitude of the long lived component determined by integration over the bleach region in the fit (Table 2) a yield of $35 \%$ of 
the long lived species can be estimated, which is very reasonable. ${ }^{34}$ It should be noted that this value presents an upper limit of the actual yield of the long-lived species as, at early times, comparably strong photoinduced absorption might overlap with the ground-state bleach. On the contrary, at long delay times, the $\Delta \mathrm{OD}$ spectrum resembles the inverted ground state spectrum of T1 with only minor contributions from a broad unstructured photoinduced absorption. The absence of any noticeable contribution from photoinduced absorption at long delay times reflects the difficulty of the spectroscopic detection of holes in $\mathrm{NiO}$, which has already been pointed out by Hagfeldt and by Hammarström. ${ }^{57}, 59$ It should also be mentioned here that recent studies by the groups of Hammarström ${ }^{54}$ and Meyer ${ }^{56}$ highlighted the dependence of the charge separated state lifetime on the external bias applied to the electrode. Vacant electronic states extending well above the valence band are indeed present in NiO films; filling these states by applying a negative potential to the film in a classical three-electrode setup as the one employed here for the photoelectrochemical measurements (see below) drastically increases the lifetime of the reduced dye on the surface.

\section{Photoelectrochemical study}

The existence of a long-lived charge-separated state is a key feature for the observation of catalytic photocurrent in functional photocathodes reported in literature. ${ }^{18,20-21,55}$ This is particularly crucial when the catalyst is dissolved in solution: electron transfer from the reduced dye to the catalyst is, in this specific case, controlled by diffusion of the latter in the electrolyte; it thus occurs - at the fastest - on the nanosecond timescale.

To verify whether the long-lived species detected above for the T1-sensitized NiO films could initiate catalysis, the photoelectrochemical properties of these electrodes were investigated in aqueous sodium acetate buffer $(0.1 \mathrm{M}, \mathrm{pH}=4.5)$ in the absence and in the presence of the cobaloxime $\mathrm{H}_{2}$-evolving catalyst $\left[\mathrm{Co}\left(\mathrm{dmgBF}_{2}\right)_{2}\left(\mathrm{H}_{2} \mathrm{O}\right)_{2}\right]$ (Fig. 1), previously employed for similar purposes. $^{12,2030}$ The redox properties of the latter $\left(\mathrm{E}^{0}\left(\mathrm{Co}^{\mathrm{I} / \mathrm{I}}\right)=-0.40 \mathrm{~V}\right.$ vs NHE$)$ are suitable for $\mathrm{Co}(\mathrm{I})$ generation by electron transfer from the reduced dye to the $\mathrm{Co}(\mathrm{II})$. The latter process is exergonic with a Gibbs free energy $\left(\Delta G_{\mathrm{ET}}=E\left(\mathrm{PS}_{\mathrm{PS}}{ }^{-}\right)-E\left(\mathrm{Co}^{\mathrm{II}} / \mathrm{Co}^{\mathrm{I}}\right)\right)$ of $-0.64 \mathrm{eV}$, essential to enter the $\mathrm{H}_{2}$-evolving catalytic cycle. ${ }^{60}$

Linear sweep voltammograms (Fig. 6) were recorded first in the dark and then under visible light irradiation ( $400-800 \mathrm{~nm} ; 65 \mathrm{~mW} \cdot \mathrm{cm}^{-2} \sim 1 \mathrm{sun}$ ) on a range of potentials preventing direct $\mathrm{Co}$ (II) to 
$\mathrm{Co}(\mathrm{I})$ reduction at the electrode. Photocurrent generation was observed with an onset potential of $+0.4 \mathrm{~V}$ vs NHE.

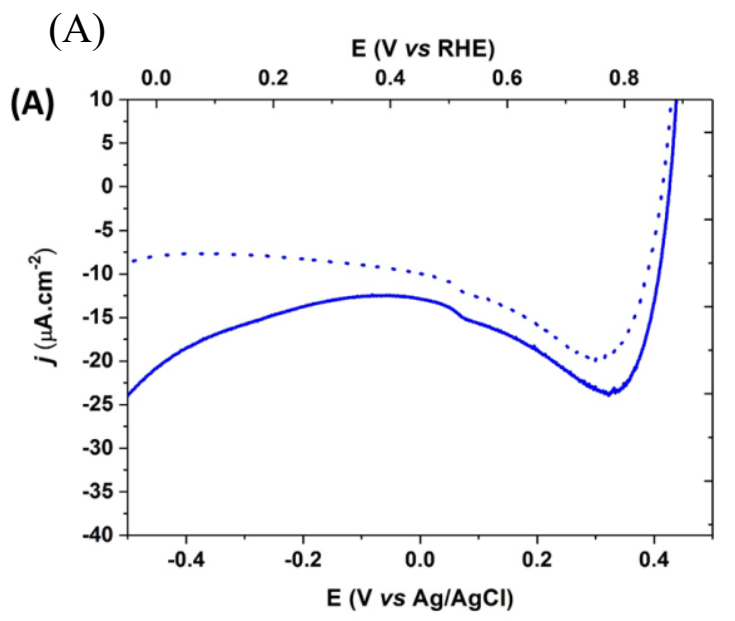

(B)

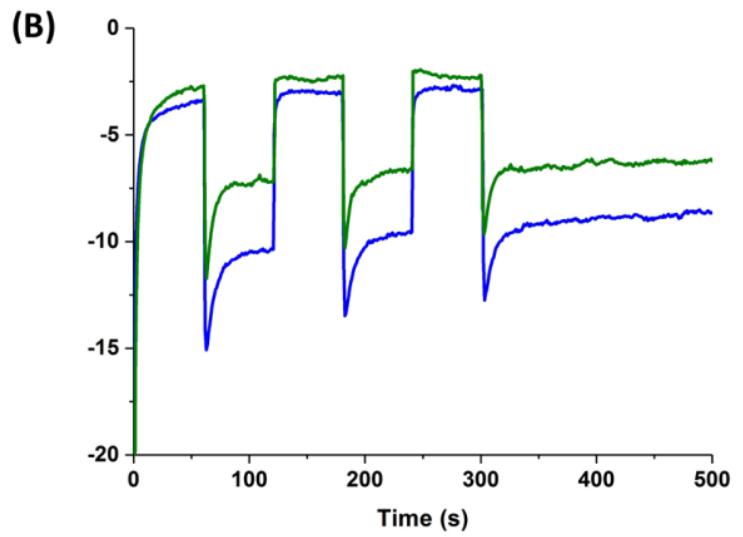

Figure 6. (A) Linear sweep voltammograms of a T1-sensitized $\mathrm{NiO}$ electrode recorded in acetate buffer $(0.1 \mathrm{M}, \mathrm{pH} 4.5)$ in the presence of $\left[\mathrm{Co}\left(\mathrm{dmgBF}_{2}\right)_{2}\left(\mathrm{H}_{2} \mathrm{O}\right)_{2}\right] \quad(1 \mathrm{mM})$, in the dark (dotted line) or under visible-light irradiation (solid line). (B) Chopped-light chronoamperometric measurements recorded in acetate buffer $(0.1 \mathrm{M}, \mathrm{pH} 4.5)$ in the presence of $\left[\mathrm{Co}\left(\mathrm{dmgBF}_{2}\right)_{2}\left(\mathrm{H}_{2} \mathrm{O}\right)_{2}\right](1 \mathrm{mM})$ at an applied potential of $0.05 \mathrm{~V}$ vs $\mathrm{RHE}$ for $\mathrm{NiO}$ electrodes sensitized by $\mathbf{T 1}$ alone (blue line) or in the presence of CDCA as co-absorbent (green line).

Taking these observations into consideration, chronoamperometric measurements were carried out at $+0.05 \mathrm{~V} v$ s. RHE $(-0.4 \mathrm{~V}$ vs. $\mathrm{Ag} / \mathrm{AgCl})$, where high photocurrent density is observed. A photocurrent density of $6 \mu \mathrm{A} \cdot \mathrm{cm}^{-2}$ was measured under chopped light irradiation at T1-sensitized $\mathrm{NiO}$ photocathodes in the presence of $\left[\mathrm{Co}\left(\mathrm{dmgBF}_{2}\right)_{2}\left(\mathrm{H}_{2} \mathrm{O}\right)_{2}\right]$ in solution (Fig. 6, Table S1). As the co-grafting of T1 with CDCA does not impact the photoinduced dynamics of the photoelectrode, the slightly lower photocurrent value recorded in the presence of CDCA (Fig. S7 and Table S1) is attributed to the lower grafting density of the T1 dye when co-adsorbed with CDCA (Experimental part and Fig. S2).

Finally, photoelectrochemical $\mathrm{H}_{2}$ generation was confirmed during prolonged chronoamperometric measurements (6 hours at $+0.05 \mathrm{~V}$ vs. RHE, Fig. S8), coupled to gas chromatography analysis of the headspace of the cell. Hydrogen was successfully detected with a faradaic efficiency of $3 \%\left(12 \mathrm{nmol}_{\mathrm{H} 2} \cdot \mathrm{cm}^{-2}\right)$, compared to $1 \%\left(3 \mathrm{nmol}_{\mathrm{H} 2} \cdot \mathrm{cm}^{-2}\right)$ in the absence of catalyst in solution (Fig. S9, Table S1). As expected from the photocurrent measurements, 
T1/CDCA co-grafted electrodes are slightly lower active (Fig. S8, Table S1). Production of low amounts of hydrogen at dye-sensitized $\mathrm{NiO}$ photocathodes in the absence of a molecular catalyst was previously observed in the literature and recently attributed to the light-driven generation of $\mathrm{Ni}$ nanoparticles at defects of the $\mathrm{NiO}$ film. ${ }^{61}$ The observation of a four-time increase in the amount of hydrogen produced per square centimeter when the cobalt catalyst is present in solution (Table S1) supports a cobalt-center molecular process. Although the results reported here are not intended to be of any practical application, the observed catalytic activity can be directly put in line with the generation of a charge-separated state long-lived enough to allow intermolecular electron transfer to the molecular catalyst in solution.

\section{Conclusion}

The field of dye-sensitized photoelectrodes for the generation of solar fuels expands rapidly both regarding the preparation of novel systems and the spectroscopic characterization of their mechanism. However, first-principles studies that include both the molecular constituents and the metal oxide electrode surface remain scarce. We demonstrate here for the first time how DFT studies can determine the structural and electronic features of the interfaces between a push-pull dye and the p-NiO (100) surface. Although theoretical calculations cannot reproduce the complex structure of mesoporous $\mathrm{NiO}$ electrodes used experimentally in prototypical dyesensitized photocathode system, theory provides a rationale for mechanistic studies and activity measurements regarding the binding modes of the dye molecules and their effect, together with solvent polarity, on the driving force for hole injection. Further work will aim at the modelling of photocathode architectures incorporating catalytic units. ${ }^{16,26}$

\section{ASSOCIATED CONTENT}

\section{Supporting Information.}

\section{AUTHOR INFORMATION}

\section{Corresponding Authors}

* Ana B. Muñoz-Garcia; E-mail: anabelen.munozgarcia@unina.it

* Benjamin Dietzek; E-mail: benjamin.dietzek@ leibniz-ipht.de

*Vincent Artero; E-mail: vincent.artero@cea.fr 


\section{Author Contributions}

\section{Notes}

The authors declare no competing financial interest.

\section{ACKNOWLEDGMENT}

This work was supported by the French National Research Agency in the framework of the "Investissements d'avenir" program (Labex program ARCANE - ANR-11-LABX-0003-01, Graduate school of Chemistry, Biology and Health of Univ. Grenoble Alpes- CBH-EUR-GS, ANR-17-EURE-0003 and ANR-15-IDEX-02), the European Research Council under the European Union's Seventh Framework Program FP/2007-2013 (ERC Grant Agreement n.306398 and COST Action CM1202 PERSPECT-H ${ }_{2} \mathrm{O}$ ), Studienstiftung des Deutschen Volkes (M.B.). The project these results are based upon was supported by the Free State of Thuringia under the number 2015 FGI 0008 and co-financed by European Union funds under the European Regional Development Fund (EFRE).

\section{REFERENCES}

1. Faunce, T.; Styring, S.; Wasielewski, M. R.; Brudvig, G. W.; Rutherford, A. W.; Messinger, J.; Lee, A. F.; Hill, C. L.; deGroot, H.; Fontecave, M.; MacFarlane, D. R.; Hankamer, B.; Nocera, D. G.; Tiede, D. M.; Dau, H.; Hillier, W.; Wang, L.; Amal, R., Artificial photosynthesis as a frontier technology for energy sustainability. Energy Environ. Sci. 2013, 6, 1074-1076.

2. Thapper, A.; Styring, S.; Saracco, G.; Rutherford, A. W.; Robert, B.; Magnuson, A.; Lubitz, W.; Llobet, A.; Kurz, P.; Holzwarth, A.; Fiechter, S.; de Groot, H.; Campagna, S.; Braun, A.; Bercegol, H.; Artero, V., Artificial Photosynthesis for Solar Fuels - an Evolving Research Field within AMPEA, a Joint Programme of the European Energy Research Alliance. Green 2013, 3, 43-57.

3. Walter, M. G.; Warren, E. L.; McKone, J. R.; Boettcher, S. W.; Mi, Q.; Santori, E. A.; Lewis, N. S., Solar water splitting cells. Chem. Rev. 2010, 110, 6446-6473.

4. Odobel, F.; Pellegrin, Y., Recent Advances in the Sensitization of Wide-Band-Gap Nanostructured p-Type Semiconductors. Photovoltaic and Photocatalytic Applications. J. Phys. Chem. Lett. 2013, 4, 2551-2564.

5. $\quad$ Brennaman, M. K.; Dillon, R. J.; Alibabaei, L.; Gish, M. K.; Dares, C. J.; Ashford, D. L.; House, R. L.; Meyer, G. J.; Papanikolas, J. M.; Meyer, T. J., Finding the Way to Solar Fuels with Dye-Sensitized Photoelectrosynthesis Cells. J. Am. Chem. Soc. 2016, 138, 13085-13102.

6. Xu, P.; McCool, N. S.; Mallouk, T. E., Water splitting dye-sensitized solar cells. Nano Today 2017, 14, 42-58.

7. Gibson, E. A., Dye-sensitized photocathodes for $\mathrm{H}_{2}$ evolution. Chem. Soc. Rev. 2017, 46, 6194-6209. 
8. Queyriaux, N.; Kaeffer, N.; Morozan, A.; Chavarot-Kerlidou, M.; Artero, V., Molecular cathode and photocathode materials for hydrogen evolution in photoelectrochemical devices. $J$. Photochem. Photobiol. C 2015, 25, 90-105.

9. Kumagai, H.; Sahara, G.; Maeda, K.; Higashi, M.; Abe, R.; Ishitani, O., Hybrid photocathode consisting of a $\mathrm{CuGaO}_{2}$ p-type semiconductor and a $\mathrm{Ru}(\mathrm{II})-\mathrm{Re}(\mathrm{I})$ supramolecular photocatalyst: non-biased visible-light-driven $\mathrm{CO}_{2}$ reduction with water oxidation. Chem. Sci. 2017, 8, 4242-4249.

10. Sahara, G.; Kumagai, H.; Maeda, K.; Kaeffer, N.; Artero, V.; Higashi, M.; Abe, R.; Ishitani, O., Photoelectrochemical Reduction of $\mathrm{CO}_{2}$ Coupled to Water Oxidation Using a Photocathode with a $\mathrm{Ru}(\mathrm{II})-\mathrm{Re}(\mathrm{I})$ Complex Photocatalyst and a $\mathrm{CoO}_{\mathrm{x}} / \mathrm{TaON}$ Photoanode. J. Am. Chem. Soc. 2016, 138, 14152-14158.

11. Wang, D.; Wang, Y.; Brady, M. D.; Sheridan, Matthew V.; Sherman, B. D.; Farnum, B. H.; Liu, Y.; Marquard, S. L.; Meyer, G. J.; Dares, C. J.; Meyer, T. J., A donor-chromophorecatalyst assembly for solar $\mathrm{CO}_{2}$ reduction. Chem. Sci. 2019, 10, 4436-4444.

12. Li, L.; Duan, L.; Wen, F.; Li, C.; Wang, M.; Hagfeldt, A.; Sun, L., Visible light driven hydrogen production from a photo-active cathode based on a molecular catalyst and organic dyesensitized p-type nanostructured NiO. Chem. Commun. 2012, 48, 988-990.

13. Ji, Z.; He, M.; Huang, Z.; Ozkan, U.; Wu, Y., Photostable p-Type Dye-Sensitized Photoelectrochemical Cells for Water Reduction. J. Am. Chem. Soc. 2013, 135, 11696-11699.

14. Fan, K.; Li, F.; Wang, L.; Daniel, Q.; Gabrielsson, E.; Sun, L., Pt-free tandem molecular photoelectrochemical cells for water splitting driven by visible light. Phys. Chem. Chem. Phys. 2014, 16, 25234-25240.

15. Li, F.; Fan, K.; Xu, B.; Gabrielsson, E.; Daniel, Q.; Li, L.; Sun, L., Organic DyeSensitized Tandem Photoelectrochemical Cell for Light Driven Total Water Splitting. J. Am. Chem. Soc. 2015, 137, 9153-9159.

16. Kaeffer, N.; Massin, J.; Lebrun, C.; Renault, O.; Chavarot-Kerlidou, M.; Artero, V., Covalent Design for Dye-Sensitized $\mathrm{H}_{2}$-Evolving Photocathodes Based on a Cobalt DiimineDioxime Catalyst. J. Am. Chem. Soc. 2016, 138, 12308-12311.

17. Click, K. A.; Beauchamp, D. R.; Huang, Z.; Chen, W.; Wu, Y., Membrane-Inspired Acidically Stable Dye-Sensitized Photocathode for Solar Fuel Production. J. Am. Chem. Soc. 2016, 138, 1174-1179.

18. Antila, L. J.; Ghamgosar, P.; Maji, S.; Tian, H.; Ott, S.; Hammarström, L., Dynamics and Photochemical H2 Evolution of Dye-NiO Photocathodes with a Biomimetic FeFe-Catalyst. $A C S$ Energy Letters 2016, 1, 1106-1111.

19. Gross, M. A.; Creissen, C. E.; Orchard, K. L.; Reisner, E., Photoelectrochemical hydrogen production in water using a layer-by-layer assembly of a $\mathrm{Ru}$ dye and Ni catalyst on NiO. Chem. Sci. 2016, 7, 5537-5546.

20. Kamire, R. J.; Majewski, M. B.; Hoffeditz, W. L.; Phelan, B. T.; Farha, O. K.; Hupp, J. T.; Wasielewski, M. R., Photodriven hydrogen evolution by molecular catalysts using $\mathrm{Al}_{2} \mathrm{O}_{3}-$ protected perylene-3,4-dicarboximide on NiO electrodes. Chem. Sci. 2017, 8, 541-549.

21. Pati, P. B.; Zhang, L.; Philippe, B.; Fernández-Terán, R.; Ahmadi, S.; Tian, L.; Rensmo, H.; Hammarström, L.; Tian, H., Insights into the Mechanism of a Covalently Linked Organic Dye-Cobaloxime Catalyst System for Dye-Sensitized Solar Fuel Devices. ChemSusChem 2017, $10,2480-2495$.

22. Wang, D.; Sheridan, M. V.; Shan, B.; Farnum, B. H.; Marquard, S. L.; Sherman, B. D.; Eberhart, M. S.; Nayak, A.; Dares, C. J.; Das, A. K.; Bullock, R. M.; Meyer, T. J., Layer-by- 
Layer Molecular Assemblies for Dye-Sensitized Photoelectrosynthesis Cells Prepared by Atomic Layer Deposition. J. Am. Chem. Soc. 2017, 139, 14518-14525.

23. Shan, B.; Nayak, A.; N. Sampaio, R.; Eberhart, M. S.; Troian-Gautier, L.; Brennaman, M. K.; Meyer, G. J.; Meyer, T. J., Direct photoactivation of a nickel-based, water-reduction photocathode by a highly conjugated supramolecular chromophore. Energy Environ. Sci. 2018, $11,447-455$.

24. Shan, B.; Nayak, A.; Brennaman, M. K.; Liu, M.; Marquard, S. L.; Eberhart, M. S.; Meyer, T. J., Controlling Vertical and Lateral Electron Migration Using a Bifunctional Chromophore Assembly in Dye-Sensitized Photoelectrosynthesis Cells. J. Am. Chem. Soc. 2018, 140, 6493-6500.

25. Pati, P. B.; Zhang, L.; Philippe, B.; Fernández-Terán, R.; Ahmadi, S.; Tian, L.; Rensmo, H.; Hammarström, L.; Tian, H., Insights into the Mechanism of a Covalently-Linked Organic Dye-Cobaloxime Catalyst System for Dye Sensitized Solar Fuel Devices. ChemSusChem 2017, 10, 2480-2495.

26. Kaeffer, N.; Windle, C. D.; Brisse, R.; Gablin, C.; Léonard, D.; Jousselme, B.; ChavarotKerlidou, M.; Artero, V., Insights into Mechanism and Aging of a noble-metal free $\mathrm{H}_{2}$-evolving Dye-Sensitized Photocathode. Chem. Sci. 2018, 9, 6721-6738.

27. Windle, C. D.; Massin, J.; Chavarot-Kerlidou, M.; Artero, V., A protocol for quantifying hydrogen evolution by dye-sensitized molecular photocathodes and its implementation for evaluating a new covalent architecture based on an optimized dye-catalyst dyad. Dalton Trans. 2018, 47, 10509-10516.

28. Shan, B.; Sherman, B. D.; Klug, C. M.; Nayak, A.; Marquard, S. L.; Liu, Q.; Bullock, R. M.; Meyer, T. J., Modulating Hole Transport in Multilayered Photocathodes with Derivatized pType Nickel Oxide and Molecular Assemblies for Solar-Driven Water Splitting. J. Phys. Chem. Lett. 2017, 8, 4374-4379.

29. Dini, D.; Halpin, Y.; Vos, J. G.; Gibson, E. A., The influence of the preparation method of NiOx photocathodes on the efficiency of p-type dye-sensitized solar cells. Coord. Chem. Rev. 2015, 304-305, 179-201.

30. Wood, C. J.; Summers, G. H.; Clark, C. A.; Kaeffer, N.; Braeutigam, M.; Carbone, L. R.; D'Amario, L.; Fan, K.; Farre, Y.; Narbey, S.; Oswald, F.; Stevens, L. A.; Parmenter, C. D. J.; Fay, M. W.; La Torre, A.; Snape, C. E.; Dietzek, B.; Dini, D.; Hammarstrom, L.; Pellegrin, Y.; Odobel, F.; Sun, L.; Artero, V.; Gibson, E. A., A comprehensive comparison of dye-sensitized $\mathrm{NiO}$ photocathodes for solar energy conversion. Phys. Chem. Chem. Phys. 2016, 18, 1072710738.

31. Ponseca, C. S.; Chábera, P.; Uhlig, J.; Persson, P.; Sundström, V., Ultrafast Electron Dynamics in Solar Energy Conversion. Chem. Rev. 2017, 117, 10940-11024.

32. Nikolaou, V.; Charisiadis, A.; Charalambidis, G.; Coutsolelos, A. G.; Odobel, F., Recent advances and insights in dye-sensitized $\mathrm{NiO}$ photocathodes for photovoltaic devices. J. Mater. Chem. A 2017, 5, 21077-21113.

33. Brautigam, M.; Kubel, J.; Schulz, M.; Vos, J. G.; Dietzek, B., Hole injection dynamics from two structurally related Ru-bipyridine complexes into $\mathrm{NiO}_{\mathrm{x}}$ is determined by the substitution pattern of the ligands. Phys. Chem. Chem. Phys. 2015, 17, 7823-7830.

34. Queyriaux, N.; Wahyuono, R. A.; Fize, J.; Gablin, C.; Wächtler, M.; Martinez, E.; Léonard, D.; Dietzek, B.; Artero, V.; Chavarot-Kerlidou, M., Aqueous Photocurrent Measurements Correlated to Ultrafast Electron Transfer Dynamics at Ruthenium Tris Diimine Sensitized NiO Photocathodes. J. Phys. Chem. C 2017, 121, 5891-5904. 
35. Han, Y.; Dillon, R. J.; Flynn, C. J.; Rountree, E. S.; Alibabaei, L.; Cahoon, J. F.; Papanikolas, J. M.; Dempsey, J. L., Interfacial electron transfer yields in dye-sensitized $\mathrm{NiO}$ photocathodes correlated to excited-state dipole orientation of ruthenium chromophores. Can. J. Chem. 2018, 96, 865-874.

36. Morandeira, A.; Boschloo, G.; Hagfeldt, A.; Hammarström, L., Photoinduced Ultrafast Dynamics of Coumarin 343 Sensitized p-Type-Nanostructured NiO Films. J. Phys. Chem. B 2005, 109, 19403-19410.

37. Morandeira, A.; Boschloo, G.; Hagfeldt, A.; Hammarström, L., Coumarin 343-NiO Films as Nanostructured Photocathodes in Dye-Sensitized Solar Cells: Ultrafast Electron Transfer, Effect of the $\mathrm{I}^{3-} / \mathrm{I}^{-}$Redox Couple and Mechanism of Photocurrent Generation. J. Phys. Chem. C 2008, 112, 9530-9537.

38. Mori, S.; Fukuda, S.; Sumikura, S.; Takeda, Y.; Tamaki, Y.; Suzuki, E.; Abe, T., ChargeTransfer Processes in Dye-Sensitized NiO Solar Cells. J. Phys. Chem. C 2008, 112, 1613416139.

39. Gardner, J. M.; Beyler, M.; Karnahl, M.; Tschierlei, S.; Ott, S.; Hammarström, L., LightDriven Electron Transfer between a Photosensitizer and a Proton-Reducing Catalyst Coadsorbed to NiO. J. Am. Chem. Soc. 2012, 134, 19322-19325.

40. Brown, A. M.; Antila, L. J.; Mirmohades, M.; Pullen, S.; Ott, S.; Hammarström, L., Ultrafast Electron Transfer Between Dye and Catalyst on a Mesoporous NiO Surface. J. Am. Chem. Soc. 2016, 138, 8060-8063.

41. Gatty, M. G.; Pullen, S.; Sheibani, E.; Tian, H.; Ott, S.; Hammarström, L., Direct evidence of catalyst reduction on dye and catalyst co-sensitized $\mathrm{NiO}$ photocathodes by midinfrared transient absorption spectroscopy. Chem. Sci. 2018, 9, 4983-4991.

42. Munoz-Garcia, A. B.; Pavone, M., Structure and energy level alignment at the dyeelectrode interface in p-type DSSCs: new hints on the role of anchoring modes from ab initio calculations. Phys. Chem. Chem. Phys. 2015, 17, 12238-12246.

43. Massin, J.; Bräutigam, M.; Kaeffer, N.; Queyriaux, N.; Field, M. J.; Schacher, F. H.; Popp, J.; Chavarot-Kerlidou, M.; Dietzek, B.; Artero, V., Dye-Sensitized PS-b-P2VP-templated Nickel Oxide Films for Photoelectrochemical Applications. Interface Focus 2015, 5, 20140083.

44. Natu, G.; Hasin, P.; Huang, Z.; Ji, Z.; He, M.; Wu, Y., Valence band-edge engineering of nickel oxide nanoparticles via cobalt doping for application in p-type dye-sensitized solar cells. ACS Appl. Mater. Interfaces 2012, 4, 5922-5929.

45. Grimme, S.; Antony, J.; Ehrlich, S.; Krieg, H., A consistent and accurate ab initio parametrization of density functional dispersion correction (DFT-D) for the 94 elements H-Pu. $J$. Chem. Phys. 2010, 132.

46. Ma, W.; Jiao, Y.; Meng, S., Predicting Energy Conversion Efficiency of Dye Solar Cells from First Principles. J. Phys. Chem. C. 2014, 118, 16447-16457.

47. Ito, S.; Miura, H.; Uchida, S.; Takata, M.; Sumioka, K.; Liska, P.; Comte, P.; Pechy, P.; Gratzel, M., High-conversion-efficiency organic dye-sensitized solar cells with a novel indoline dye. Chem. Commun. 2008, 5194-6.

48. Favereau, L.; Warnan, J.; Pellegrin, Y.; Blart, E.; Boujtita, M.; Jacquemin, D.; Odobel, F., Diketopyrrolopyrrole derivatives for efficient NiO-based dye-sensitized solar cells. Chem. Commun. 2013, 49, 8018-20.

49. Ishow, E.; Guillot, R.; Buntinx, G.; Poizat, O., Photoinduced intramolecular chargetransfer dynamics of a red-emitting dicyanovinyl-based triarylamine dye in solution. $J$. Photochem. Photobiol. A 2012, 234, 27-36. 
50. Ishow, E.; Clavier, G.; Miomandre, F.; Rebarz, M.; Buntinx, G.; Poizat, O., Comprehensive investigation of the excited-state dynamics of push-pull triphenylamine dyes as models for photonic applications. Phys. Chem. Chem. Phys. 2013, 15, 13922-13939.

51. Zhu, H.; Wang, X.; Ma, R.; Kuang, Z.; Guo, Q.; Xia, A., Intramolecular Charge Transfer and Solvation of Photoactive Molecules with Conjugated Push-Pull Structures. ChemPhysChem 2016, 17, 3245-3251.

52. Kovalenko, S. A.; Ernsting, N. P.; Ruthmann, J., Femtosecond hole-burning spectroscopy of the dye DCM in solution: the transition from the locally excited to a charge-transfer state. Chem. Phys. Lett. 1996, 258, 445-454.

53. Dietzek, B.; Pascher, T.; Sundström, V.; Yartsev, A., Appearance of coherent artifact signals in femtosecond transient absorption spectroscopy in dependence on detector design. Laser Physics Letters 2007, 4, 38-43.

54. D'Amario, L.; Antila, L. J.; Pettersson Rimgard, B.; Boschloo, G.; Hammarstrom, L., Kinetic Evidence of Two Pathways for Charge Recombination in NiO-Based Dye-Sensitized Solar Cells. J. Phys. Chem. Lett. 2015, 6, 779-83.

55. Shan, B.; Farnum, B. H.; Wee, K.-R.; Meyer, T. J., Generation of Long-Lived Redox Equivalents in Self-Assembled Bilayer Structures on Metal Oxide Electrodes. J. Phys. Chem. C 2017, 121, 5882-5890.

56. Dillon, R. J.; Alibabaei, L.; Meyer, T. J.; Papanikolas, J. M., Enabling Efficient Creation of Long-Lived Charge-Separation on Dye-Sensitized NiO Photocathodes. ACS Appl. Mater. Interfaces 2017, 9, 26786-26796.

57. D'Amario, L.; Fohlinger, J.; Boschloo, G.; Hammarstrom, L., Unveiling hole trapping and surface dynamics of NiO nanoparticles. Chem. Sci. 2018, 9, 223-230.

58. Odobel, F.; Pellegrin, Y.; Gibson, E. A.; Hagfeldt, A.; Smeigh, A. L.; Hammarstrom, L., Recent advances and future directions to optimize the performances of p-type dye-sensitized solar cells. Coord. Chem. Rev. 2012, 256, 2414-2423.

59. Boschloo, G.; Hagfeldt, A., Spectroelectrochemistry of Nanostructured NiO. J. Phys. Chem. B 2001, 105, 3039-3044.

60. Artero, V.; Chavarot-Kerlidou, M.; Fontecave, M., Splitting water with cobalt. Angew. Chem. Int. Ed. 2011, 50, 7238-7266.

61. Hoogeveen, D. A.; Fournier, M.; Bonke, S. A.; Nattestad, A.; Mishra, A.; Bäuerle, P.; Spiccia, L.; Mozer, A. J.; Simonov, A. N., Origin of Photoelectrochemical Generation of Dihydrogen by a Dye-Sensitized Photocathode without an Intentionally Introduced Catalyst. $J$. Phys. Chem. C 2017, 121, 25836-25846. 